\title{
Inhibition of Bacterial Surface Colonization by Immobilized Silver Nanoparticles Depends Critically on the Planktonic Bacterial Concentration
}

Stacy M. Wirth ${ }^{1}$, Alex J. Bertuccio ${ }^{1}$, Feng Cao $^{1}$, Gregory V. Lowry ${ }^{2}$ and Robert D. Tilton ${ }^{1,3^{*}}$

Center for Complex Fluids Engineering and Center for Environmental Implications of Nanotechnology, ${ }^{1}$ Department of Chemical Engineering, ${ }^{2}$ Department of Civil and Environmental Engineering, and ${ }^{3}$ Department of Biomedical Engineering, Carnegie Mellon University, Pittsburgh, PA 15213

*Corresponding author. Tel: 1-412-268-1159, email: tilton@cmu.edu

\begin{abstract}
Immobilization of antimicrobial silver nanoparticles (AgNPs) on surfaces has been proposed as a method to inhibit biofouling or as a possible route by which incidental releases of AgNPs may interfere with biofilms in the natural environment or in wastewater treatment. This study addresses the ability of planktonic Pseudomonas fluorescens bacteria to colonize surfaces with pre-adsorbed AgNPs. The ability of the AgNP-coated surfaces to inhibit colonization was controlled by the dissolved silver in the system, with a strong dependence on the initial planktonic cell concentration in the suspension, i.e., a strong inoculum effect. This dependence was attributed to a decrease in dissolved silver ion bioavailability and toxicity caused by its
\end{abstract}


binding to cells and/or cell byproducts. Therefore, when the initial cell concentration was high $\left(\sim 1 \times 10^{7} \mathrm{CFU} / \mathrm{mL}\right)$, an excess of silver binding capacity removed most of the free silver and allowed both planktonic growth and surface colonization directly on the AgNP-coated surface. When the initial cell concentration was low $\left(\sim 1 \times 10^{5} \mathrm{CFU} / \mathrm{mL}\right), 100 \%$ killing of the planktonic cell inoculum occurred and prevented colonization. When an intermediate initial inoculum concentration $\left(\sim 1 \times 10^{6} \mathrm{CFU} / \mathrm{mL}\right)$ was sufficiently large to prevent $100 \%$ killing of planktonic cells, even with $99.97 \%$ initial killing, the planktonic population recovered and bacteria colonized the AgNP-coated surface. In some conditions, colonization of AgNP-coated surfaces was enhanced relative to silver-free controls, and the bacteria demonstrated a preferential attachment to AgNP-coated, rather than bare, surface regions. The degree to which the bacterial concentration dictates whether or not surface-immobilized AgNPs can inhibit colonization has significant implications both for the design of antimicrobial surfaces and for the potential environmental impacts of AgNPs.

KEYWORDS: silver nanoparticles, antimicrobial surface, antifouling, biofilm, inoculum effect, silver toxicity, nanoEHS

\section{INTRODUCTION}

Bacterial surface colonization has significance in both natural and engineered systems. Surface colonization may lead to biofilms, adherent three-dimensional bacterial communities surrounded by a secreted matrix of extracellular polymeric substance (EPS). Though biofilms are integral components of natural and certain engineered environments (e.g., wastewater 
treatment plants), unwanted surface colonization or biofilm formation can pose a health threat and negatively impact industrial processes.

Bacterial adhesion on medical implants is a major problem in healthcare $[1,2]$. Once formed, implant-associated biofilms are often unresponsive to the host's immune response and to systemically administered antibiotics, leaving implant replacement as the only viable treatment [3]. Deleterious effects are also associated with bacterial colonization and biofilm formation in industrial processing equipment and on marine surfaces, leading to degraded fluid flow and heat transfer, corrosion, and increased ship hull drag [4-6]. Biofilms on food processing equipment produce contamination and spoilage $[5,7]$.

High costs associated with biofilm formation have driven research into antifouling surfaces that resist bacterial colonization as the precursor to biofilm formation $[2,3,6,8]$. A common strategy is to impart bactericidal activity directly to surfaces [3]. Because of its broad spectrum antimicrobial properties $[9,10]$ and the low occurrence of silver resistance compared to traditional antibiotics $[8,11]$, incorporation of silver in ionic or nanoparticulate form to prevent colonization and biofilm formation has been proposed $[12,13]$. Commercial materials containing silver nanoparticles (AgNPs) immobilized on or embedded in their surfaces are becoming increasingly prevalent [14]. Although bacteria residing in established biofilms show increased tolerance of AgNPs compared to their planktonic counterparts [15, 16], this surface coating strategy may yet be effective at colonization inhibition since unprotected planktonic cells are involved in the initial attachment stage. Indeed, biofilm-inhibiting properties of AgNPincorporating surfaces have been demonstrated in vitro [17-22]. Clinical trials have had less success [23-25]. 
The potential for surface-adherent AgNPs to prevent bacterial colonization also has environmental implications [26-28]. Commercial usage of AgNPs for antimicrobial technologies has prompted concerns that their release to the environment could have detrimental effects on microbes that are crucial to ecosystem function $[29,30]$. It is perceived that nanoparticle adhesion to environmental surfaces will reduce their bioavailability and toxicity to most organisms.[28, 31, 32] However, such surfaces are also substrates for bacterial colonization, and biofilms are the most prevalent mode of bacterial existence in the environment [33, 34]. Therefore, adhesion of biocidal AgNPs to environmental surfaces might adversely affect important ecological processes.

Recent studies indicate that dissolved $\mathrm{Ag}^{+}$, which disrupts cell function by complexing with DNA and disrupting protein function by reacting with sulfur-containing amino acid residues, is the main toxic agent associated with AgNPs. While the nanoparticles serve mainly as a source of $\mathrm{Ag}^{+}$[35-38], there are situations in which distinct nanoparticle effects are implicated [39-42].

AgNP dissolution and the toxicity of dissolved silver depends on media conditions [32, 43, 44], and silver ion binding to macromolecular solutes (for example proteins or humic acid) can decrease its toxicity $[15,25,45]$. The antimicrobial performance of surfaces based on silver ion release is therefore likely to depend strongly on the local composition. This can make it difficult to extrapolate from in vitro studies to field or application environments. It is therefore important to determine the relative importance of dissolved silver and direct bacterial interaction with surface-adherent nanoparticles, particularly as it relates to inhibition of bacterial colonization on AgNP-laden surfaces. 
Another complicating factor in the interpretation of in vitro tests is the choice of initial bacterial inoculum concentration in the planktonic suspension bathing the surface. Inoculum concentrations that have been tested vary greatly between investigations $\left(10^{3}-10^{10} \mathrm{CFU} / \mathrm{mL}\right.$ for studies cited here) [17-22], but with little direct comparison of concentration effects within a single study. Recent investigations of suspended AgNP toxicity to planktonic bacterial cultures demonstrate that the degree of cell killing is highly dependent on the initial cell concentration [46-48]. The inoculum concentration controls the silver to biomass ratio in the system. The importance of this ratio is also indicated by recent evidence that exposure to sublethal concentrations of suspended AgNPs stimulates biofilm formation, perhaps as an environmental stress response [49]. The effect of inoculum concentration on the anti-colonization performance of silver-laden surfaces must be considered explicitly, both for antifouling surface engineering and for understanding the environmental implications of AgNPs.

The objectives of this work were to determine the influence of bacterial inoculum concentration on the degree to which AgNPs adsorbed on a solid surface prevent surface colonization by a model biofilm-forming, Gram negative bacterium, Pseudomonas fluorescens (ATCC13525) and to isolate the effects of direct bacterial interaction with AgNP-laden surfaces from the effects of dissolved silver released from the nanoparticles. Gram negative bacteria tend to be more vulnerable to silver ion and AgNP toxicity than Gram positive bacteria that have thicker cell walls that appear to hinder silver uptake.[50-53] Thus, this study focuses on a more vulnerable class of microorganism that one might expect to be less likely to tolerate an AgNPbased anti-fouling system. The importance of the initial inoculum concentration was assessed for both short-term $(<24 \mathrm{~h}$ ) and long-term (up to $96 \mathrm{~h}$ ) resistance to colonization and, in some 
cases, progression to biofilm formation, on both AgNP-coated and uncoated surface regions. Results were compared to control experiments with no silver present anywhere in the system.

These experiments indicated that colonization inhibition by AgNP-coated surfaces was controlled by the bioavailable dissolved silver in the system, with a strong dependence on the starting inoculum concentration. In conditions where the dissolved silver was insufficient to cause $100 \%$ killing of the initial inoculum, the planktonic population eventually recovered and colonization occurred, regardless of the presence of AgNPs on the surface. This was consistent with measurements of the effect of bacterial concentration on silver binding to suspended bacteria. This has implications for the suitability of AgNP coatings to produce biofilm-resistant materials and for the environmental implications of AgNPs adhered to environmental surfaces.

\section{EXPERIMENTAL SECTION}

Surface immobilized AgNPs. Silver nanoparticles used in this study were described previously [54]. The particular particles, denoted as Ag PVP 8 in the prior publication, were stabilized by polyvinylpyrrolidone (PVP) (MW 55,000) and had a 7.8 $\pm 4.6 \mathrm{~nm}$ diameter based on TEM [54]. Particles were obtained as a concentrated (> $500 \mathrm{ppm})$ aqueous dispersion and stored in the dark at $4^{\circ} \mathrm{C}$.

Glass coverslips $(22 \times 22 \mathrm{~mm}$, No. 1.5, Fisher Scientific) were used as colonization substrates. Coverslips were cleaned by 30 min bath sonication (Branson 1200, Branson Ultrasonics Corp.) in a 10\% solution of RBS 35 detergent concentrate (Thermo Scientific), 20 min treatment with Nochromix (Sigma-Aldrich) dissolved in sulfuric acid (technical grade, 9398\%, Fisher Scientific), $20 \mathrm{~min}$ treatment in $6 \mathrm{~N} \mathrm{HCl}$ (BDH Chemicals), and $30 \mathrm{~min}$ in $10 \mathrm{mM}$ 
$\mathrm{NaOH}$. Coverslips were rinsed thoroughly with ultrapure water after each step. Finally, they were dried under a pure nitrogen jet and sterilized by UV irradiation for 15 minutes (Spectroline Model EN-180, $365 \mathrm{~nm}, 4 \mathrm{~W})$. Coverslips were used immediately after preparation.

The stock AgNP dispersion was diluted in autoclave sterilized ultrapure water (Barnstead Nanopure, $>18 \mathrm{M} \Omega \mathrm{cm}$ resistivity) to a 10ppm final concentration, and the dispersed particle size distribution was characterized by dynamic light scattering (DLS) (Zetasizer Nano ZS, Malvern Instruments). $5 \mathrm{~mL}$ aliquots of this dispersion were then dispensed into sterile $50 \mathrm{~mL}$ polypropylene centrifuge tubes (Beckman Coulter). One cleaned, UV-sterilized glass coverslip was placed in each tube so that it was half submerged in the AgNP dispersion. The other half remained dry, thereby depositing AgNPs on half of the surface. Coverslips were handled using flame-sterilized forceps in all steps. A freshly prepared $10 \mathrm{ppm}$ AgNP dispersion was used for each coverslip.

Coverslips half submerged in AgNP dispersions were incubated in the dark at room temperature $\left(23 \pm 2^{\circ} \mathrm{C}\right)$ for $1 \mathrm{~h}$ without shaking. Each coverslip was then rinsed by slowly pouring $800 \mathrm{~mL}$ autoclave-sterilized, ultrapure water over it. Rinsed coverslips were immediately transferred to new $50 \mathrm{~mL}$ centrifuge tubes containing $15 \mathrm{~mL}$ sterile minimal Davis media (MDM, described below) for use in bacteria adhesion experiments. Coverslips were rotated $90^{\circ}$ during the transfer so that the boundary between the AgNP-coated and uncoated portions was vertical (avoiding differences in colonization on coated and uncoated regions resulting from submersion depth), and the entire coverslip was submerged in MDM. This setup makes it possible to easily distinguish effects from bulk dissolved silver and from direct interaction with adsorbed AgNPs, since the same liquid (with the exact same composition in all regards, 
including dissolved silver concentration) bathes both the uncoated and AgNP-coated surface regions.

Some of the rinsed coverslips were transferred to tubes containing ultrapure water for darkfield microscopy examination. Strong light scattering associated with localized surface plasmon resonance allows AgNPs to be identified in this way [55]. This was done with a Zeiss AxioObserver Z1 inverted microscope equipped with a HAL100 halogen illuminator. Coverslips were imaged wet using a 40× LD Plan-NEOFLUAR objective (Zeiss). Images were collected at a 1s exposure (AxioCam MRm) to count the AgNPs adhered to the coated surface region. Images from the uncoated region were also acquired to estimate the contribution of extraneous dust particles or microscopic glass defects to the total counts. Particle counting was performed with Image J 1.45s image analysis software.

Contact angle measurement. AgNP-coated and uncoated coverslips were incubated in $25 \mathrm{~mL}$ sterilized MDM for 20 hours with $160 \mathrm{rpm}$ orbital mixing, rinsed with purified water and gently dried under a purified nitrogen stream. A Ramè-Hart contact angle imaging system was used to measure the advancing and receding contact angles for a drop of purified water deposited on each surface.

Bacterial strain and culture conditions. The bacterial strain was Pseudomonas fluorescens ATCC 13525. All cell culture and AgNP exposure work was performed in minimal Davis media (MDM) containing $0.7 \mathrm{~g} / \mathrm{L} \mathrm{K} \mathrm{HPO}_{4}\left(\geq 99 \%\right.$, J.T. Baker), $0.2 \mathrm{~g} / \mathrm{L} \mathrm{KH} \mathrm{KH}_{4}(\geq 99 \%$, J.T. Baker), 1 g/L $\left(\mathrm{NH}_{4}\right)_{2} \mathrm{SO}_{4}(\geq 99 \%$, Sigma-Aldrich), $0.5 \mathrm{~g} / \mathrm{L}$ sodium citrate ( $\geq 99 \%$, Sigma- 
Aldrich), $0.1 \mathrm{~g} / \mathrm{L} \mathrm{MgSO}_{4} \cdot 7 \mathrm{H}_{2} \mathrm{O}$ ( $\geq 98 \%$, Sigma-Aldrich), and $1 \mathrm{~g} / \mathrm{L}$ glucose (Sigma-Aldrich) as carbon source at $\mathrm{pH} 7.2 \pm 0.1$. This media was chosen for its comparatively low ionic strength ( $\sim 50 \mathrm{mM})$ and absence of chloride. For each experiment, a starting culture was prepared by inoculating autoclave-sterilized MDM with a $P$. fluorescens frozen stock $\left(-80^{\circ} \mathrm{C}\right)$, then growing aerobically overnight at $23 \pm 2^{\circ} \mathrm{C}$ with $160 \mathrm{rpm}$ orbital mixing. Growth was monitored via optical density at $600 \mathrm{~nm}\left(\mathrm{OD}_{600}\right)$ in $1 \mathrm{~cm}$ pathlength polystyrene cuvettes (SpectraMax M2, Molecular Devices).

\section{Minimum inhibitory concentration (MIC) and minimum bactericidal concentration}

(MBC). MIC and MBC were determined for AgNPs and for ionic silver introduced as $\mathrm{AgNO}_{3}$. P. fluorescens cultures in logarithmic growth were diluted with MDM and a predetermined volume of $\mathrm{AgNO}_{3}$ solution or $\mathrm{AgNP}$ dispersion to yield samples with either $\mathrm{OD}_{600}=0.01$ or $\mathrm{OD}_{600}=0.001$, with varying silver concentrations, in black polystyrene clear-bottomed wellplates (Corning Costar). Two-fold serial dilutions ranged from 0.98 to $500 \mathrm{ppb}$ for $\mathrm{Ag}^{+}$or 9.8 to $5000 \mathrm{ppb}$ for AgNP for $\mathrm{OD}_{600}=0.01$ cultures and from 0.098 to $50 \mathrm{ppb}$ for $\mathrm{Ag}^{+}$or 0.98 to 500 ppb for AgNP for $\mathrm{OD}_{600}=0.001$ cultures. All concentrations are ppb of Ag. One well-plate column was used for bacteria-free silver controls and another for silver-free bacteria controls. The $\mathrm{OD}_{600}$ was recorded for each well immediately after filling and again after $24 \mathrm{~h}$, and the MIC was identified as the smallest $\mathrm{Ag}^{+}$or $\mathrm{AgNP}$ concentration that yielded no increase in $\mathrm{OD}_{600}$. To determine the MBC, $100 \mu \mathrm{L}$ samples taken from wells from the MIC experiments for all concentrations at and above the MIC were spread on nutrient agar. The MBC was identified as the lowest silver concentration that yielded no colonies after 24 hour growth on agar. 
Bacterial surface colonization. Appropriate volumes of the overnight bacterial cultures were added to the centrifuge tubes containing AgNP half-coated coverslips in MDM to give either $\mathrm{OD}_{600}=0.01\left(\sim 1 \times 10^{7} \mathrm{CFU} / \mathrm{mL}\right)$ or $0.001\left(\sim 1 \times 10^{6} \mathrm{CFU} / \mathrm{mL}\right)$ in a total $25 \mathrm{~mL}$ volume. Silver-free controls contained clean, UV-sterilized coverslips without AgNPs. Control samples containing AgNP half-coated coverslips but no bacteria were also examined. Tubes were shaken at $200 \mathrm{rpm}$ on an orbital shaker, with loose caps to maintain aerobic conditions, in the dark, at room temperature $\left(23 \pm 2^{\circ} \mathrm{C}\right)$.

After $1 \mathrm{~h}$ incubation, the bulk liquid in the tubes was serially diluted and plated onto nutrient agar. Colonies were counted after $48 \mathrm{~h}$ growth at room temperature $\left(23 \pm 2^{\circ} \mathrm{C}\right)$ to calculate the total culture sample viability. If no growth was observed, it indicated greater than $99.99 \%$ ("4 log") killing of the $\sim 1 \times 10^{6} \mathrm{CFU} / \mathrm{mL}$ culture or $99.999 \%$ ("5 log") killing of the $\sim 1 \times 10^{7} \mathrm{CFU} / \mathrm{mL}$ culture.

Further planktonic growth in the cultures suspended above coverslips was monitored by periodic $\mathrm{OD}_{600}$ and plate count measurements. In some cases noted below, after $24 \mathrm{~h}$ incubation in the original media, coverslips were gently rinsed with sterile MDM and transferred to tubes containing $25 \mathrm{~mL}$ fresh $\mathrm{MDM}$ to replenish depleted nutrients and test the role of nutrient depletion on growth and surface colonization.

Dissolved silver analysis. The dissolved silver concentration (consisting of free ionic silver and any other dissolved silver species, i.e., excluding suspended nanoparticulate Ag) in the media bathing the AgNP-coated coverslips from the cell-free tubes was measured by inductively coupled plasma mass spectrometry (ICP-MS, Agilent 7700x) at different time points. Small samples for ICP-MS analysis were taken from the bulk liquid in the tubes and diluted in $\mathrm{HNO}_{3}$ 
(Aristar plus grade, BDH Chemicals) to finish with 5 vol\% $\mathrm{HNO}_{3}$. For tubes containing bacteria, the dissolved silver concentration was measured just prior to addition of the cells to determine the starting silver concentration at the time of inoculation. Then, after $1 \mathrm{~h}$ incubation with cells, new samples of the bulk liquid were collected and filtered using Amicon® Ultra-4 centrifugal filter units with $3 \mathrm{kDa}$ molecular weight cutoffs (Millipore) to remove cells and macromolecular cell products plus any silver to which they may have been complexed. Filtrates were acidified to a concentration of $5 \mathrm{vol} \% \mathrm{HNO}_{3}$ and analyzed by ICP-MS to determine the amount of "free silver" in the liquid. The difference between the filtrates and the pre-inoculation (cell-free) samples provides the amount of silver that had bound to cells (or macromolecular cell products retained by the filter). This process was repeated after $48 \mathrm{~h}$ and $72 \mathrm{~h}$ incubation. As a negative control, samples from cell-free tubes were also filtered and analyzed by ICP-MS to determine the extent to which dissolved silver might be removed by binding to the filter.

The partitioning between dissolved and bacterial biomass-associated $\mathrm{Ag}^{+}$was investigated independently. P. fluorescens in logarithmic growth was diluted with MDM and predetermined volumes of $\mathrm{AgNO}_{3}$ solution to prepare cultures with $\mathrm{OD}_{600}=0.001,0.01$ or 0.045. Total $\mathrm{Ag}^{+}$concentrations ranged from 0.25 to $50 \mathrm{ppb}$. Cultures were orbitally mixed for 1 hour at $160 \mathrm{rpm}$. Afterwards, a $3 \mathrm{~mL}$ aliquot was collected and held for silver analysis, while a separate $4 \mathrm{~mL}$ aliquot was centrifugally filtered as above. $3 \mathrm{~mL}$ of the filtrate was collected. Both the unfiltered sample and the filtrate were treated with $180 \mu \mathrm{L}$ concentrated $\mathrm{HNO}_{3}$ and $90 \mu \mathrm{L}$ $\mathrm{H}_{2} \mathrm{O}_{2}\left(30 \%\right.$, Fisher Scientific), heated for $15 \mathrm{~min}$ at $100^{\circ} \mathrm{C}$ in a digital heat block (VWR International) and allowed to cool. Silver concentrations were then determined using ICP-MS. 
Microscopic analysis of bacterial surface colonization. The number and viability of bacteria adhered on coverslips were measured at various time points using LIVE/DEAD ${ }^{\circledR}$ BacLight ${ }^{\mathrm{TM}}$ bacterial viability staining (Invitrogen Corp.) and epifluorescence microscopy. Cell counting was only performed when bacteria were present in a monolayer or less; otherwise, three dimensional biofilm formation was simply noted when it occurred. The BacLight kit contains propidium iodide (PI) and SYTO9 fluorescent dyes that differentially stain bacteria based on membrane integrity. This difference correlates with viability [56], and we use that association here.

To prepare coverslips for imaging, they were removed from the tubes, transferred to 40 $\mathrm{mL}$ of a $1 \mathrm{mM} \mathrm{NaCl}$ rinse solution and gently swirled by hand for 10 seconds. After two such rinses, the surface was covered with $300 \mu \mathrm{L}$ BacLight staining mixture (60 $\mu \mathrm{M}$ PI and $10 \mu \mathrm{M}$ SYTO9 in $1 \mathrm{mM} \mathrm{NaCl}$ ) and incubated in the dark for 20 minutes. Afterwards, coverslips were rinsed again in $40 \mathrm{~mL} 1 \mathrm{mM} \mathrm{NaCl}$. The unstained (bottom) side of the coverslip was carefully dried with laboratory tissue (Kimwipe) and the coverslip was transferred to the microscope stage. The stained (top) side of the coverslip did not dry during any of these steps.

BacLight stained cells were observed using a Zeiss Axio Observer Z1 epifluorescence microscope equipped with an HBO 100 illuminating system. Appropriate dichromatic filter sets were selected to fit the excitation/emission spectra of the BacLight fluorophores. The filter sets used for SYTO9 and PI were filter set AF488 (Zeiss Filterset 10) and filter set AO (Chroma 31011 acridine orange filter set), respectively. Images were collected with an AxioCam MRm camera. The total cell counts and viability of cells in the images were quantified by the method described and validated in Supplementary Material. Bacterial calibration standards analyzed using this method showed excellent correlation between the expected and the measured 
viabilities. Experiments verified that AgNPs do not interfere with this assay (Supplementary Material).

\section{RESULTS AND DISCUSSION}

Surfaces with Adsorbed AgNPs. The intensity-weighted hydrodynamic diameter distribution of the AgNPs dispersed in purified water, as determined by DLS, indicates that the dispersion consisted mainly of primary particles with some aggregates (Supplementary Material, Figure S3). The number-weighted diameter distribution shows one peak near $10 \mathrm{~nm}$, corresponding to primary particles, consistent with the $7.8 \pm 4.6 \mathrm{~nm}$ diameter reported by TEM.

The average particle number density on the AgNP coated coverslip regions was $(3.0 \pm 0.43) \times 10^{5}$ particles $/ \mathrm{mm}^{2}$ (mean \pm standard deviation), as determined by darkfield imaging (Supplementary Material, Figure S4). Counts from uncoated regions were 580 \pm 350 particles $/ \mathrm{mm}^{2}$ indicating a negligible contribution from extraneous dust or coverslip defects to the total particle counts. Comparing particle counts between multiple coverslips prepared on different days, by one way ANOVA, showed no statistical difference $(\mathrm{P}=0.4)$ indicating the reproducibility of the particle adsorption procedure. After $24 \mathrm{~h}$ incubation in cell-free MDM, there was no significant decrease in particle counts based on average counts from three different coverslips $(\mathrm{P}=0.10)$. Thus, AgNP desorption is not significant over the timescale of the bacterial incubation experiments.

Growth and Viability of Planktonic Bacteria. The effect of adsorbed AgNPs on bacterial surface colonization will be discussed below, but first the MIC and $\mathrm{MBC}$ of $\mathrm{AgNO}_{3}$ and $\mathrm{AgNPs}$ measured in planktonic cultures will be discussed, followed by the effect that AgNPs adsorbed 
on glass coverslips have on the growth and viability of planktonic bacteria in the media bathing such coverslips. It will be shown that the planktonic population dynamics controls whether adsorbed AgNPs are able to prevent surface colonization on the AgNP-coated surfaces.

Both MIC and MBC were significantly higher for dispersed AgNPs than for $\mathrm{Ag}^{+}$(as $\left.\mathrm{AgNO}_{3}\right)$. For $\mathrm{OD}_{600}=0.001$ cultures, the $\mathrm{Ag}^{+}$and $\mathrm{AgNP} \mathrm{MIC}$ were $4.2 \pm 3.7 \mathrm{ppb}(\mathrm{n}=15)$ and $23 \pm 14 \mathrm{ppb}(\mathrm{n}=12)\left(\mathrm{P}=3 \times 10^{-5}\right)$, respectively, while the $\mathrm{Ag}^{+}$and AgNP MBC were 4.9 $\pm 3.1 \mathrm{ppb}$ $(\mathrm{n}=11)$ and $31 \pm 0 \mathrm{ppb}(\mathrm{n}=7)\left(\mathrm{P}=2 \times 10^{-11}\right)$, respectively. When the cell concentration was increased to $\mathrm{OD}_{600}=0.01$, the $\mathrm{Ag}^{+}$and $\mathrm{AgNP}$ MIC increased to $20 \pm 14 \mathrm{ppb}(\mathrm{n}=23)$ and $140 \pm 100 \mathrm{ppb}(\mathrm{n}=16)\left(\mathrm{P}=6 \times 10^{-8}\right)$, respectively. The $\mathrm{Ag}^{+}$and AgNP MBC increased to $32 \pm 21$ $\mathrm{ppb}(\mathrm{n}=12)$ and $156 \pm 0 \mathrm{ppb}(\mathrm{n}=7)\left(\mathrm{P}=2 \times 10^{-13}\right)$, respectively. Values are reported as mean \pm standard deviation. A zero reported standard deviation simply indicates that each MBC determination corresponded to the same serial dilution. The observed dependence of the MIC and $\mathrm{MBC}$ on the P. fluorescens concentration, for both silver forms, indicates an inoculum effect for silver toxicity, to be discussed further below. 
The viable cell concentration (determined by plate counts on nutrient agar) of a planktonic culture with an initial $\mathrm{OD}_{600}=0.001$ inoculum, after $1 \mathrm{~h}$ incubation in the presence of the AgNP half-coated coverslip, was $143.5 \pm 135.7 \mathrm{CFU} / \mathrm{mL}$. This was $99.97 \pm 0.3 \%$ less than the viable concentration measured after $1 \mathrm{~h}$ incubation with silver-free coverslips, $(5.4 \pm 2.8) \times 10^{5}$ $\mathrm{CFU} / \mathrm{mL}$. Silver-free coverslips served as the negative controls for all experiments. With a higher inoculum concentration, corresponding to $\mathrm{OD}_{600}=0.01$, no statistical difference $(\mathrm{P}=0.56)$ was observed between planktonic cell counts from the cultures with silver-free or AgNP halfcoated coverslips after $1 \mathrm{~h}$ incubation, $(4.3 \pm 1.9) \times 10^{6}$ and $(3.7 \pm 3.0) \times 10^{6} \mathrm{CFU} / \mathrm{mL}$, respectively.

Planktonic growth curves (Figure 1) also showed a minimal effect from the AgNP halfcoated coverslips for the higher concentration $\mathrm{OD}_{600}=0.01$ culture, in contrast to the significant effect that adsorbed AgNPs had on the $\mathrm{OD}_{600}=0.001$ culture. In the presence of the AgNP halfcoated coverslip, the higher concentration culture had a slight lag in growth compared to the silver-free control, indicating a transient inhibitory effect from the dissolved silver. However, once these cultures entered log growth, there was no significant difference between the growth constants for the silver-free and silver-exposed cultures, $0.55 \pm 0.09 \mathrm{~h}^{-1}$ and $0.59 \pm 0.05 \mathrm{~h}^{-1}$, respectively. 

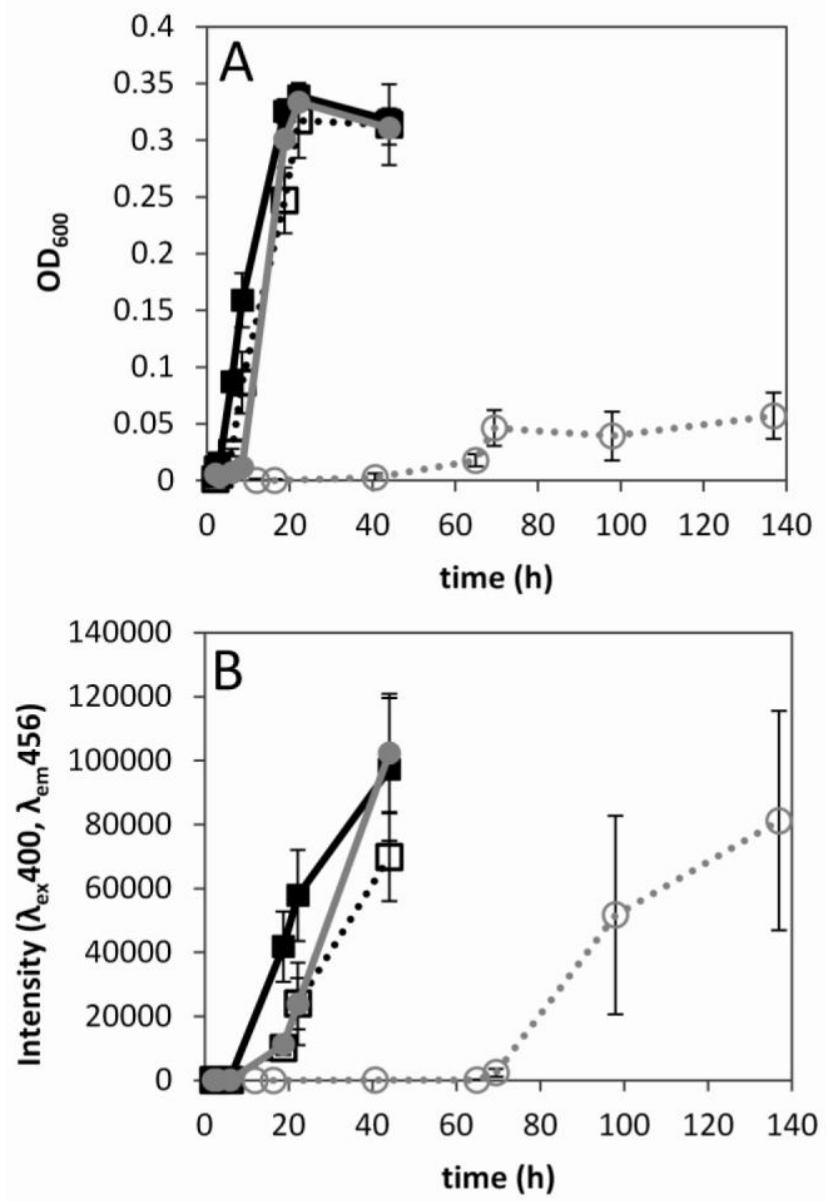

Figure 1. Planktonic cell growth indicated by $\mathrm{OD}_{600}(\mathrm{~A})$ and fluorescence emission at $456 \mathrm{~nm}$ with excitation wavelength of $400 \mathrm{~nm}$ (B) in the bulk liquid bathing coverslips. Except for a slight lag, growth in the $\mathrm{OD}_{600}=0.01$ cultures exposed to the AgNP coated coverslips (open black squares) was similar to growth in the silver-free control cultures (closed black squares). When an initial $\mathrm{OD}_{600}=0.001$ culture was used, growth was significantly delayed in the culture that was incubated with AgNP half-coated coverslips (open grey circles) compared to the case with silver-free coverslips (closed grey circles). Fluorescence (B) produced by the bacteria in AgNP exposed cultures eventually recovered to values similar to the silver-free control. Error bars represent standard deviations based on measurements from three separate experiments.

In the more dilute $\mathrm{OD}_{600}=0.001$ starting culture, growth in the presence of the AgNP half-coated coverslip was greatly delayed compared to the silver-free control (Figure 1, open gray circles). However, at long times (> $48 \mathrm{~h}$ ) growth was evident, indicating silver had not killed $100 \%$ of the starting cell population and that remaining viable cells were capable of 
reproducing in the presence of silver. In these dilute culture experiments with AgNPs, $\mathrm{OD}_{600}$ measurements are not accurate representations of cell concentration, since these cells were observed to be growing in macroscopic, suspended flocs. These do not contribute to the OD measurements as individually dispersed cells would. These flocs were consistently observed in the low cell concentration cultures incubated with AgNP half-coated coverslips, but not in any other conditions. They were also never observed in cell-free controls, eliminating the possibility that they were contaminant organisms. Since the flocs are problematic in OD measurements, fluorescence measurements were also made to give some indication of cell activity in flocculating cultures. P. fluorescens produces a soluble, fluorescent siderophore (Supplementary Material, Figures S5 and S6) [57]. Although total siderophore production is not necessarily proportional to cell density, production indicates cell activity. Fluorescence production in silvertreated cultures reached similar values to those in silver-free cultures (Figure 1B) at long times, suggesting that the cell cultures recovered significant activity at longer times.

When the initial inoculum concentration was decreased by dilution to an expected $\mathrm{OD}_{600}$ of 0.0001 ("expected" because an OD of 0.0001 is below the spectrophotometer resolution), no growth or viability was detectable in the presence of an AgNP half-coated coverslip up to $96 \mathrm{~h}$ of incubation, nor was any colonization observed. In silver-free control experiments at this low initial $\mathrm{OD}_{600}$, planktonic growth and surface colonization were both significant after $72 \mathrm{~h}$ (Supplementary Material, Figure S7). This indicates that adherent AgNPs were sufficient to kill $100 \%$ of the planktonic bacteria in the $\mathrm{OD}_{600}=0.0001$ inoculum, and only in such circumstances could surface colonization be prevented.

Decreased efficacy with increased bacterial concentration for conventional antibiotics has been observed previously and is known as the inoculum effect $[58,59]$. The hypothesis for the 
difference in planktonic viability loss between the different initial inoculum concentrations is that the free dissolved silver concentration decreased due to silver binding to the cells themselves and/or to their byproducts. The fraction of total silver in the bound form would increase with cell concentration, with cells and byproducts serving as a silver sink. To test this, silver concentrations in the bulk liquid bathing the coverslips were measured before and after removal of cell-bound silver by centrifugal ultrafiltration. The silver in the filtrate is defined as "free silver."

The results in Figure 2 show that a significant fraction of the dissolved silver was removed by filtration for both starting cell concentrations. Filtration of cell-free controls did not significantly reduce the silver concentration $(\mathrm{P}=0.3)$, indicating that neither the possible presence of desorbed AgNPs in the bulk liquid (which would be removed by the $3 \mathrm{kDa}$ filter) nor dissolved silver binding to the filter itself was significant. The cell-free control data indicate that the amount of dissolved silver released by the AgNP-coated coverslips increases over at least 72 h. The free silver concentration in the $\mathrm{OD}_{600}=0.001$ starting culture filtrate after $1 \mathrm{~h}$ was $49 \pm 12 \%$ of that in the filtrate from the cell-free control. Silver removal was far more extensive in the $\mathrm{OD}_{600}=0.01$ starting culture, with no free silver detected in the filtrate after $1 \mathrm{~h}$ incubation with the cells, or at any later time up to $72 \mathrm{~h}$. Some free silver was detected in the $\mathrm{OD}_{600}=0.001$ culture after 1 and $45 \mathrm{~h}$ incubations, but unlike the cell-free case, the concentration did not increase between 1 and $45 \mathrm{~h}$. At $72 \mathrm{~h}$, the cell concentration in that culture had increased due to cell growth (based on $\mathrm{OD}_{600}$ ) and the free silver concentration had decreased to a very low level. This is attributable to more extensive silver binding by the growing bacterial population. 


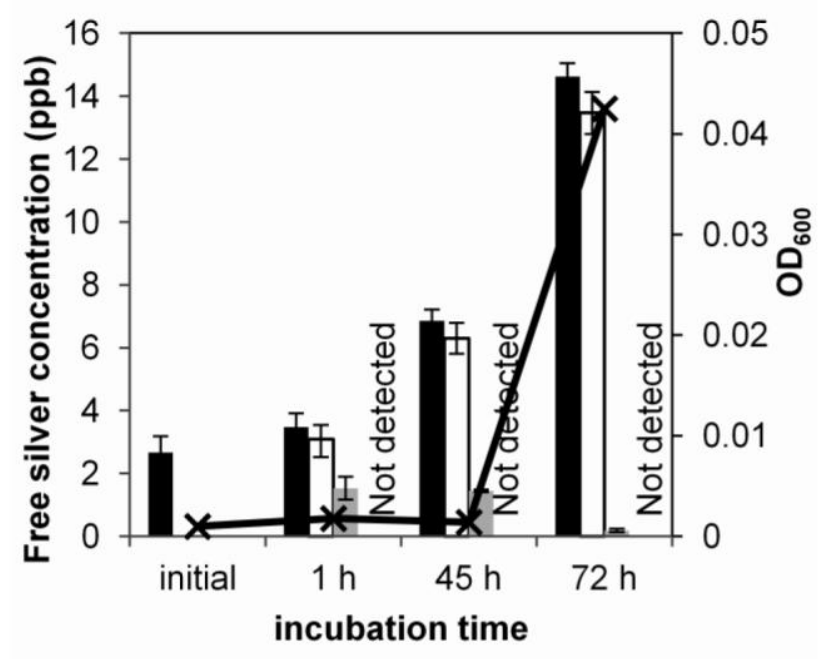

Figure 2. Dissolved silver concentration in the bulk liquid bathing AgNP half-coated coverslips showed an increase in dissolved silver with time in the cell-free controls (black bars). When these samples were filtered on $3 \mathrm{kDa}$ ultrafiltration devices, silver concentration was not significantly affected $(\mathrm{P}=0.3)$ (open bars). Large decreases in dissolved silver concentrations were observed when the bulk liquid from tubes containing cells from initial inocula corresponding to $\mathrm{OD}_{600}=0.001$ (grey bars) or $\mathrm{OD}_{600}=0.01$ (not detected) were filtered. No silver was detected in any of the $\mathrm{OD}_{600}=0.01$ filtrates. The black line $(x)$ shows the $\mathrm{OD}_{600}$ of the $\mathrm{OD}_{600}$ $=0.001$ starting culture at the various time points.

The results in Figure 2 are consistent with the hypothesis that the bacteria themselves, or their macromolecular byproducts, bind dissolved silver. By effectively decreasing the free silver concentration that is bioavailable to interact with other cells, this decreases its antimicrobial effect. Similar decreases in toxicity have been observed when $\mathrm{Ag}^{+}$is bound to humic acid in solution [15]. If suspension phase binding of silver to viable or nonviable cells and/or cell products is sufficient to keep the free silver concentration low, then planktonic bacteria populations are able to recover and overwhelm dissolved silver's antimicrobial effect.

Note that silver complexation to biomass in the $\mathrm{OD}_{600}=0.001$ culture suppressed the free silver concentration to levels that never exceeded $2 \mathrm{ppb}$ in Figure 2. This falls just below the $\sim 4$ $\mathrm{ppb} \mathrm{MIC}$ for $\mathrm{Ag}^{+}$. Thus, planktonic growth in the $\mathrm{OD}_{600}=0.001$ inoculum culture is initially 
slow, but the culture retains viability, as is evident in the $\mathrm{OD}_{600}$ increase in Figure 2 at $72 \mathrm{~h}$. Between 45 and $72 \mathrm{~h}$, the planktonic population increased significantly, reaching $\mathrm{OD}_{600}=0.045$. This increase in biomass was accompanied by the free silver decreasing to barely detectable levels (Figure 2).

This is corroborated by Figure 3, which shows the degree to which silver ion added as $\mathrm{AgNO}_{3}$ binds to planktonic $P$. fluorescens, and/or its products in suspension, at cell concentrations spanning the range of the surface colonization experiments. The extent of binding is significant and strongly dependent on cell concentration. Figure 3 indicates that cells and/or byproducts in an $\mathrm{OD}_{600}=0.045$ bacterial suspension bind $88 \%$ of the silver at total silver concentrations as high as $42 \mathrm{ppb}$. Thus, the $\mathrm{OD}_{600}=0.045$ culture, corresponding to the $72 \mathrm{~h}$ population that grew from the $\mathrm{OD}_{600}=0.001$ inoculum (Figure 2), could maintain the free silver concentration at only a few ppb for total silver ion concentrations as large as $\sim 42 \mathrm{ppb}$. The black bars in Figure 2, corresponding to cell-free control experiments where all silver is free, indicated that the total silver concentration released from the adherent AgNPs over $72 \mathrm{~h}$ never exceeded $15 \mathrm{ppb}$. This is less than the $20 \mathrm{ppb}$ MIC for a planktonic culture with $\mathrm{OD}_{600}=0.01$ (that is, a more dilute culture than the $\mathrm{OD}_{600}=0.045$ culture that existed at $72 \mathrm{~h}$ ). In experiments with the $\mathrm{OD}_{600}=0.01$ inoculum, no free silver was detected in the media bathing the AgNP halfcoated coverslips at any time. This is consistent with the equilibrium $\mathrm{Ag}^{+}$binding data in Figure 3. For the total silver concentrations of $\sim 4$ to $6 \mathrm{ppb}$ that Figure 2 indicates were released from AgNP-coated coverslips over 1 to 45 h, Figure 3 shows that nearly all of the released silver would be in the bound form for $\mathrm{OD}_{600}=0.01$ cultures, even without further planktonic growth.

It is evident that silver binding allows the planktonic population to grow in these experiments. The inoculum effect that is manifested as a strong dependence of MIC and MBC 
on cell concentration is apparent in the propagation of planktonic cultures in suspension above AgNP-coated coverslips.

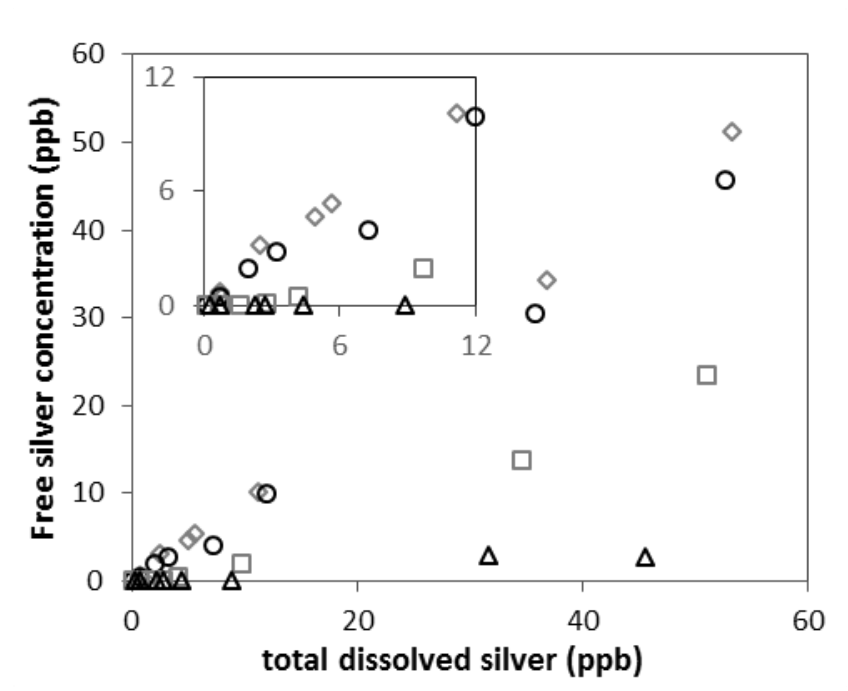

Figure 3. Free silver concentrations for $\mathrm{AgNO}_{3}$ added to planktonic $P$. fluorescens cultures in MDM, as measured by ICP-MS after filtration with a $3 \mathrm{kDa}$ cutoff. Cell-free controls (open diamonds) showed minimal decreases in free silver after filtration while $\mathrm{OD}_{600}=0.001$ (open circles), $\mathrm{OD}_{600}=0.01$ (open squares) and $\mathrm{OD}_{600}=0.045$ (open triangles) bacterial cultures decreased the free silver concentration to different degrees. The inset highlights low concentration data.

Bacterial Colonization on AgNP-Coated Surfaces. When the dissolved silver concentration was insufficient to cause $100 \%$ planktonic bacterial killing, long term recovery of the planktonic population occurred, even when $99.97 \%$ of the starting culture was killed during the first hour of incubation $\left(\mathrm{OD}_{600}=0.001\right.$ inoculum $)$. However, it is conceivable that bacterial surface colonization could possibly still have been impeded by direct interactions with AgNPs on the surface even after the planktonic population would recover. Surface colonization was therefore measured on three different surfaces: clean coverslips in silver-free media ("silver free"), the AgNP-coated regions of half-coated coverslips ("AgNP-coated"), and the uncoated 
regions of half-coated coverslips ("uncoated"). In the latter two cases, the AgNP-coated and uncoated surface regions were bathed by the same liquid.

For the higher starting bacterial concentration $\left(\mathrm{OD}_{600}=0.01, \sim 1 \times 10^{7} \mathrm{CFU} / \mathrm{mL}\right)$, surface colonization was measured at $20 \mathrm{~h}$. Representative images of BacLight stained coverslips, as well as the results of viability and attached cell count analyses are shown in Figure 4. Cells were observed to attach to all surfaces, and the overall viability of the attached bacteria was high (> 90\%) in all cases, including the cells attached to the AgNP-coated and to uncoated regions of half-coated coverslips. A one-way ANOVA analysis showed no statistical difference for either viability $(\mathrm{P}=0.79)$ or cell counts $(\mathrm{P}=0.25)$ on the silver-free, uncoated or AgNP-coated surfaces.

Figure 4 also shows that colonization at $20 \mathrm{~h}$ did not produce a complete bacterial monolayer, even though the planktonic cell concentration was very high at the time of measurement $\left(3.3 \times 10^{8} \mathrm{CFU} / \mathrm{mL}\right)$. Total growth in these cultures was dominated by planktonic growth, likely limiting the ability for adherent bacteria to grow into a mature biofilm. At $20 \mathrm{~h}$, planktonic growth had reached stationary phase (Figure 1) indicating nutrient depletion in these cultures. 

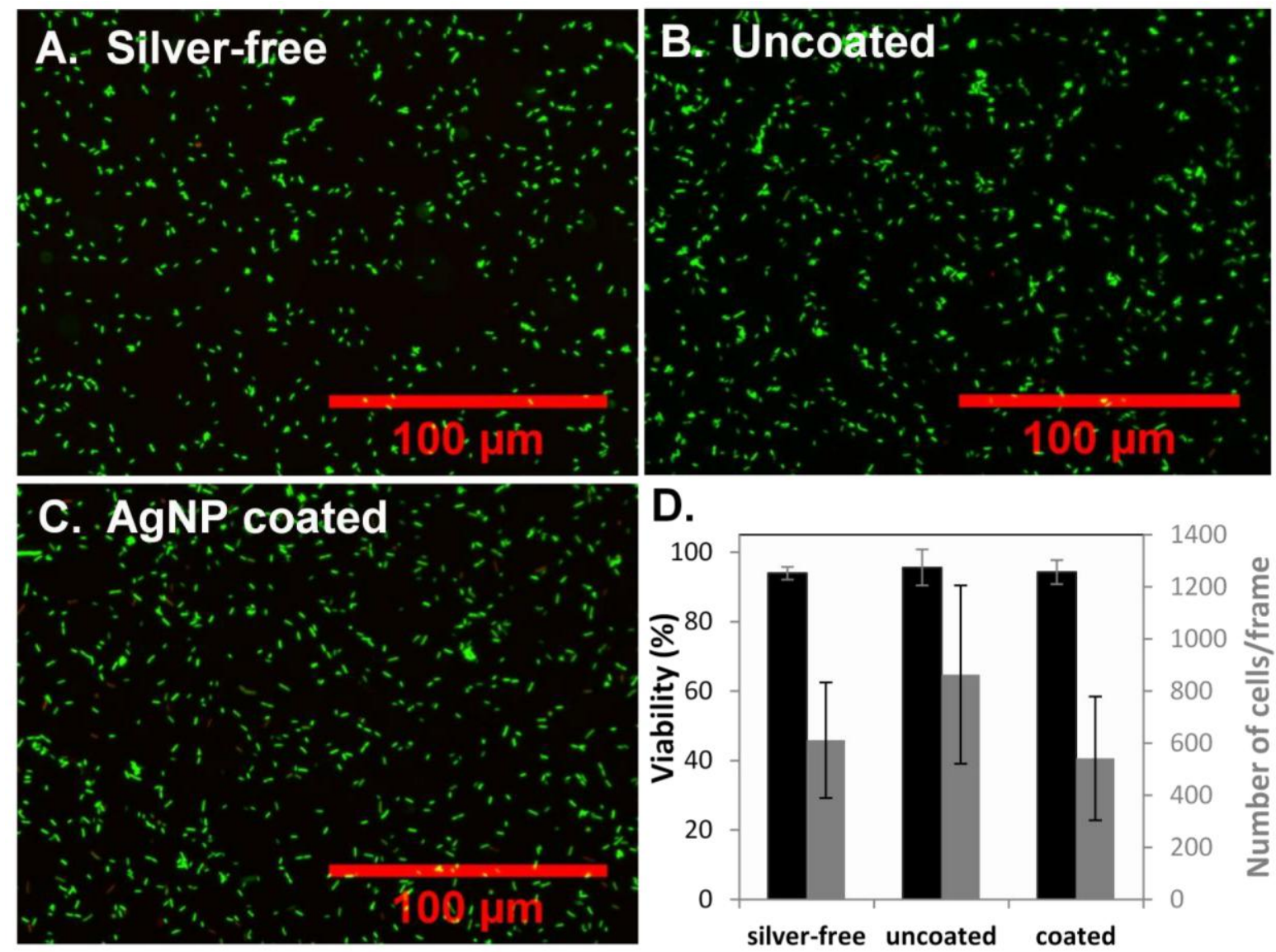

Figure 4. Representative images of BacLight stained bacteria adhered to a silver-free control coverslip (A), the uncoated region of a coverslip half-coated with AgNPs (B), and the AgNP coated region of the half-coated coverslip (C) after $20 \mathrm{~h}$ incubation with the $\mathrm{OD}_{600}=0.01\left(\sim 1 \times 10^{7}\right.$ $\mathrm{CFU} / \mathrm{mL}$ ) inoculum $P$. fluorescens culture. These are false color overlays of images collected with the AF488 (green) and AO (red) filter sets. The average viability (black bars) and cell count per image (frame size is $37300 \mu \mathrm{m}^{2}$ ) (grey bars) are plotted in (D). Error bars represent one standard deviation based on 4, 3, and 6 replicates for the silver-free, uncoated, and AgNP coated conditions, respectively. For each replicate experiment, at least five different, randomly selected images from each of the surface regions were analyzed.

To test whether the adherent bacterial layer could progress to a three-dimensional biofilm if the nutrient limitation were lifted, coverslips incubated for $20 \mathrm{~h}$ in the initial cell culture were gently rinsed in MDM to remove planktonic cells and transferred to fresh, cell-free MDM. After $24 \mathrm{~h}$ in the new media, this process was repeated and an additional $24 \mathrm{~h}$ of growth 
was allowed before imaging. A visible biofilm was observed by eye on both the silver-free control and the AgNP-coated coverslips. Microscopy confirmed that significant biofilm formation had occurred on all surfaces (Figure 5), indicating that a mature biofilm could form on the AgNP-coated coverslip if provided with sufficient nutrients.

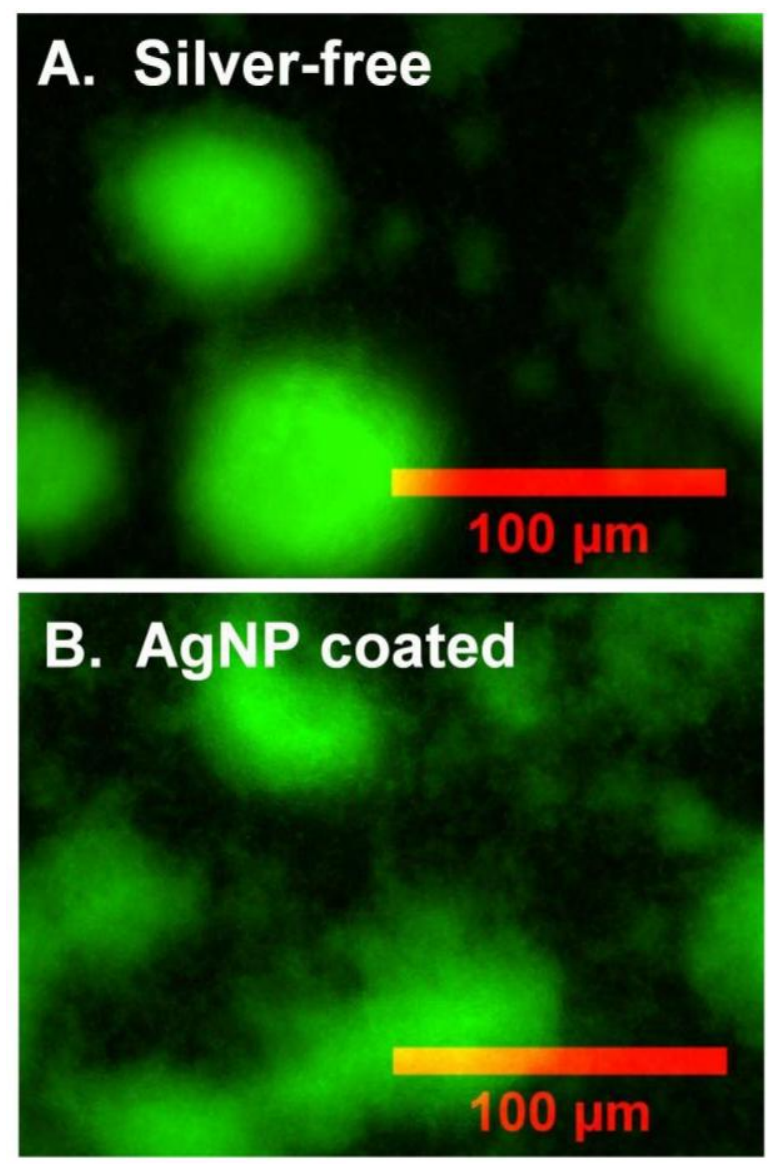

Figure 5. BacLight stained bacterial biofilms adhered to a silver-free control coverslip (A) and an AgNP-coated coverslip (B) after a total of $68 \mathrm{~h}$ growth (from $\mathrm{OD}_{600}=0.01$ starting culture, transferred to new MDM after $20 \mathrm{~h}$, second transfer after an additional $24 \mathrm{~h}$ ). Large clusters indicate significant biofilm formation, even on the AgNP-coated surface. 
Surface colonization from an $\mathrm{OD}_{600}=0.001$ inoculum was also measured. Recall that dissolved silver affected planktonic growth from the $\mathrm{OD}_{600}=0.001\left(\sim 1 \times 10^{6} \mathrm{CFU} / \mathrm{mL}\right)$ inoculum to a much greater extent than the $\mathrm{OD}_{600}=0.01\left(\sim 1 \times 10^{7} \mathrm{CFU} / \mathrm{mL}\right)$ inoculum. A similar effect of the bacterial inoculum concentration on bacterial surface colonization and subsequent biofilm formation on AgNP-coated surfaces might be expected. After $20 \mathrm{~h}$ incubation with the $\mathrm{OD}_{600}=$ 0.001 inoculum, significant differences were observed between the silver-free coverslips and the AgNP-coated and uncoated coverslip regions (Figures 6 and 7).

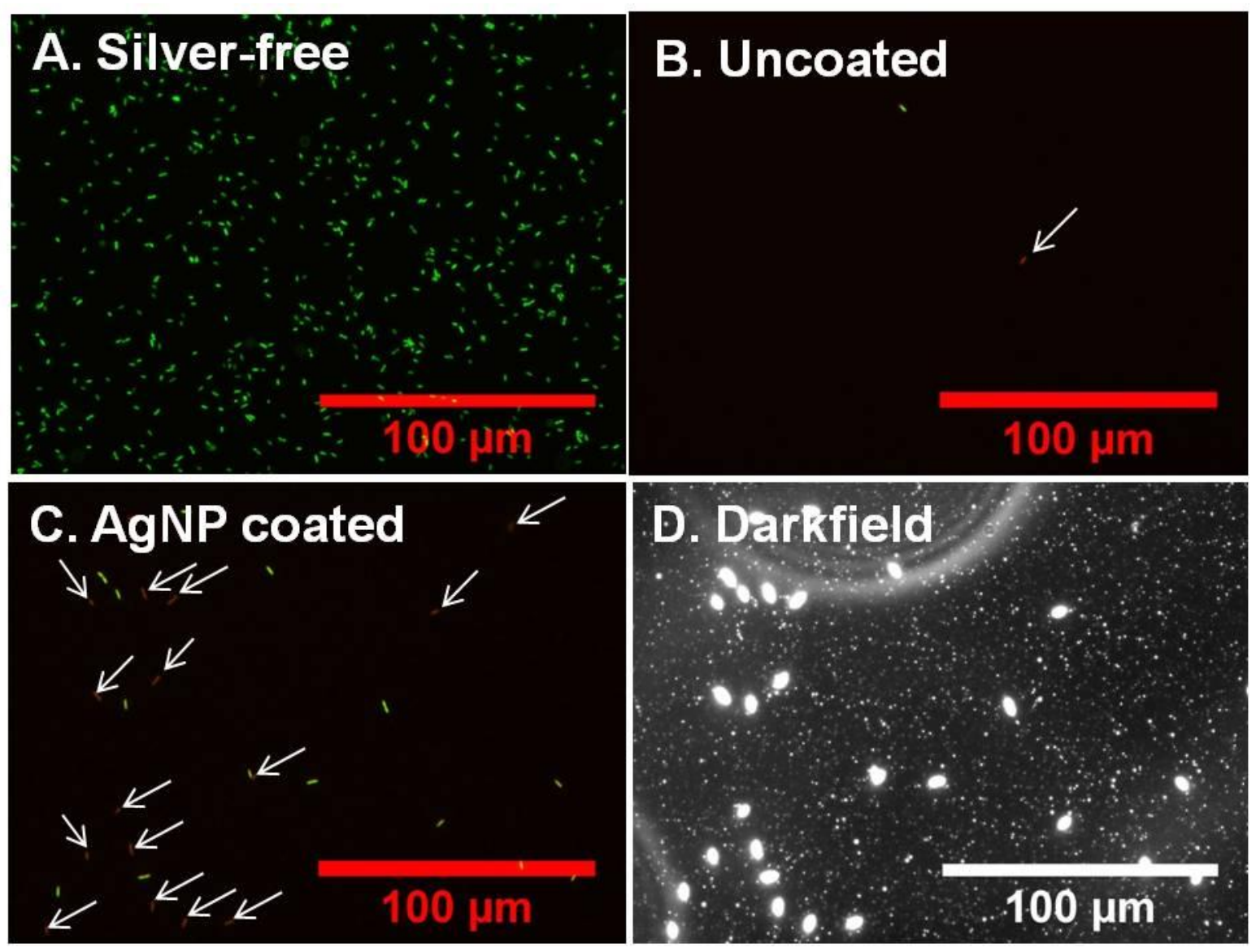


Figure 6. Representative images of BacLight stained bacteria adhered to a silver-free control coverslip (A), the uncoated region of a coverslip half-coated with AgNPs (B), and the AgNPcoated region of the half-coated coverslip (C) after $20 \mathrm{~h}$ incubation with the $\mathrm{OD}_{600}=0.001$ $\left(\sim 1 \times 10^{6} \mathrm{CFU} / \mathrm{mL}\right)$ inoculum $P$. fluorescens culture. These are false color overlays of images collected with the AF488 (green) and AO (red) filter sets. "Viable" cells in these images appear as bright green, while "non-viable" cells appear as very faint red (marked with arrows). The same field of view from (C) was also imaged in darkfield (D) to show that AgNPs remain adhered to the coverslip. Large bright objects in (D) are cells, both viable and non-viable, while small dots show light scattered from adherent AgNPs. Every cell observed in (C) appears in (D).

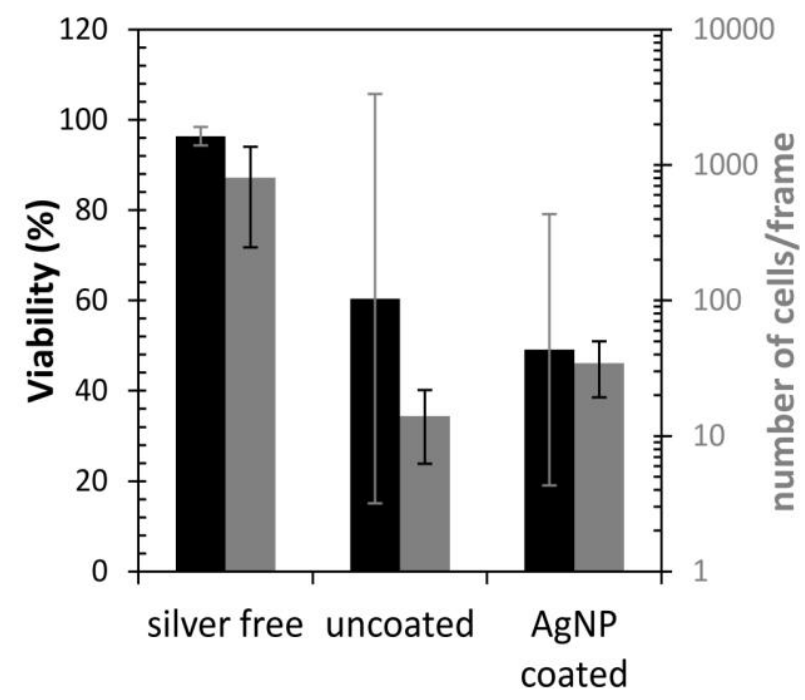

Figure 7. Average viability (black) and number of adherent cells per image (frame size is 37300 $\mu \mathrm{m}^{2}$ ) (grey) on silver-free control coverslips and the uncoated and AgNP-coated regions of halfcoated coverslips after $20 \mathrm{~h}$ incubation with the $\mathrm{OD}_{600}=0.001\left(\sim 1 \times 10^{6} \mathrm{CFU} / \mathrm{mL}\right)$ inoculum $P$. fluorescens culture. Error bars for the viability results represent standard deviations based on 5, 3 , and 5 replicates in the silver-free, uncoated, and AgNP-coated cases, respectively. For the cell counts, there were 7, 9, and 11 replicates. For each replicate experiment, at least five different images from each of the different surface regions were analyzed.

The number of bacteria adhered to coated or uncoated regions of the AgNP half-coated coverslips after $20 \mathrm{~h}$ was significantly lower than the number adhered to the silver-free control coverslips in these $\mathrm{OD}_{600}=0.001$ experiments. This was consistent with the large difference in 
the planktonic populations present at this time in the presence or absence of silver (Figure 1). However, even though the planktonic population was exactly the same for the uncoated and AgNP-coated regions of each half-coated coverslip, the number of bacteria adhered in the AgNPcoated region was significantly greater than it was in the uncoated region $(\mathrm{P}=0.001)$. Greater adherent cell numbers on the AgNP-coated surface were observed by direct comparison of the coated and uncoated regions of the same coverslip in each replicate experiment. Darkfield microscopy (Figure 6D) confirmed that AgNPs remained adsorbed on the coated coverslips during the incubation with bacteria.

It was hypothesized that enhanced colonization of the AgNP-coated surface was due to a physical interaction between the adsorbed AgNPs and the bacteria. In other words, perhaps the presence of AgNPs simply increased the adhesion energy of bacteria behaving merely as colloidal particles, in a purely physical process without a biological basis. To test this, an $\mathrm{OD}_{600}=0.001$ culture was killed by DNA-damaging ultraviolet radiation (G30T8 UV lamp, 30 $\mathrm{W}, 254 \mathrm{~nm}$ ) before being exposed to the surfaces. At this wavelength, UV light causes DNA damage and bacterial inactivation, with minimal damage to other cellular components [60]. Therefore, it is expected that the bacterial surface chemical properties will not be altered significantly, except for the presence of membrane proteins whose expression is under active cellular control. Plate counts of UV-treated cultures confirmed at least 6 log killing of the bacteria in planktonic suspension before the start of these adhesion experiments.

The number of bacteria adhering to AgNP-coated surfaces from the UV-killed cultures (4 \pm 2 cells/frame) was very small compared to the number adhering from viable cultures with the same $\mathrm{OD}_{600}\left(65 \pm 38\right.$ cells). Even increasing the UV-killed culture $\mathrm{OD}_{600}$ to 0.01 did not result in the amount of adhesion observed in the viable cell case, giving only $19 \pm 6$ cells/frame. In fact, at 
this higher concentration of killed cells, significantly more cells were adhered to the uncoated region than to the AgNP-coated region of the coverslips $\left(\mathrm{P}=4.9 \times 10^{-5}\right)$, the opposite of what was observed for the viable cultures.

Collectively, these results indicate that there is an as yet unknown biological reason for the increased adhesion of cells on the AgNP coated surfaces. Additionally, the low numbers of adhering killed cells suggests that the nonviable cells observed on the AgNP-coated surfaces became nonviable after they initially adhered as viable cells. Viability appears to be a necessary condition for the preferential bacterial adhesion to the AgNP-coated surface. It is unclear at this point whether the increased colonization of the AgNP-coated region is caused by some biological recognition of the AgNPs on the surface or whether it may be related to changes in substrate surface properties or roughness that promote the ability of active bacteria to establish an anchorage and colonize the surface. Surface topography has previously been shown to influence bacterial adhesion [61-63]. Although adhered AgNPs did not render the coverslips hydrophobic, they did become slightly less hydrophilic. Clean coverslips incubated in MDM were perfectly wetted by water, while the advancing and receding contact angles of water on AgNP-coated coverslips were $10.7 \pm 1^{\circ}$ and $6.9 \pm 0.9^{\circ}$, respectively, suggesting that surface physico-chemical processes probably are not responsible for preferential attachment to AgNPcoated surface regions. Further investigation into the cause of the preferential adhesion of viable bacteria on AgNP-coated surfaces remains a subject of interest.

A significant fraction of the adherent bacteria on the AgNP-coated surface were shown to be viable by BacLight staining in the $\mathrm{OD}_{600}=0.001$ inoculum experiments, even though the surface was coated with biocidal AgNPs (Figure 7). In a study of bacterial growth on glasses doped with silver ion, Valappil and colleagues [64] noted that a layer of dead bacteria could 
provide a protective layer that enables additional bacterial proliferation. The observation that a significant fraction of bacteria were observed to be viable with less than a full bacterial monolayer in the present study suggests that such a sacrificial layer is not a necessary condition for bacterial colonization on AgNP-coated surfaces. Biofilm formation on the AgNP-coated coverslips from the $\mathrm{OD}_{600}=0.001$ starting culture was also assessed at longer times $(48,72$, and $96 \mathrm{~h})$. Coverslips were kept in the same media for the entire time period; no media switch was performed. At these longer times, planktonic growth was evident (Figure 1). Figure 8 shows that significant biofilm formation did occur at these longer times on both uncoated and AgNPcoated regions. By $96 \mathrm{~h}$, significant formation of thick biofilms (observable by eye) with large cell clusters had occurred on the AgNP-coated coverslips for triplicate runs of the experiments, indicating the lack of any significant long-term anti-biofilm effect of the AgNP-coated surfaces at these inoculum concentrations.

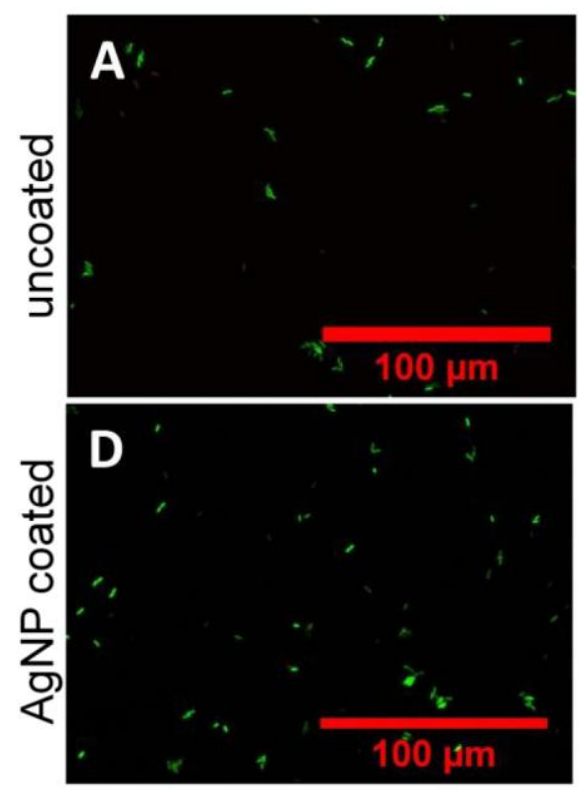

$48 \mathrm{~h}$
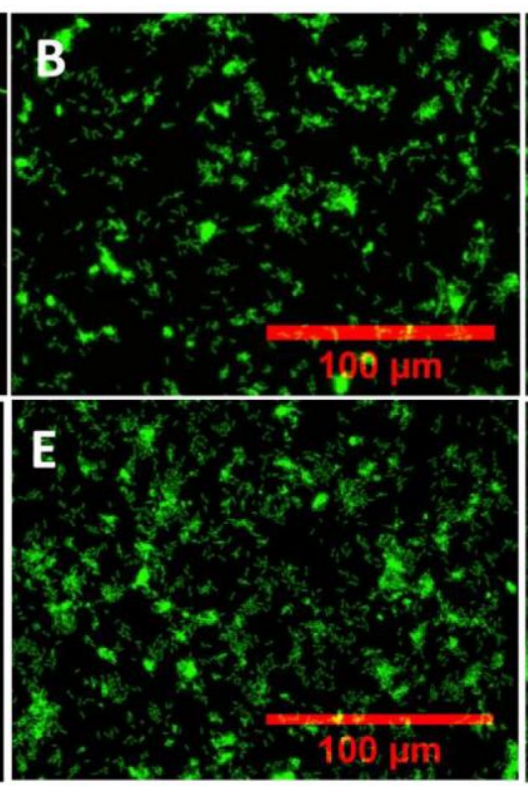

$72 \mathrm{~h}$
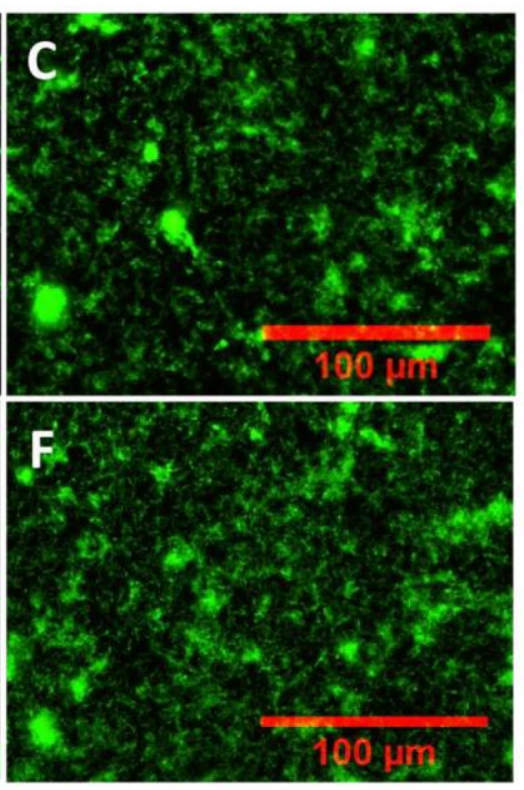

$96 \mathrm{~h}$ 
Figure 8. Representative images of BacLight stained bacteria adhered to the uncoated (A,B,C) and AgNP-coated (D,E,F) regions of half-coated coverslips after $48 \mathrm{~h}(\mathrm{~A}, \mathrm{D}), 72 \mathrm{~h}(\mathrm{~B}, \mathrm{E})$ and $96 \mathrm{~h}$ $(\mathrm{C}, \mathrm{F})$ of growth from $\mathrm{OD}_{600}=0.001\left(\sim 1 \times 10^{6} \mathrm{CFU} / \mathrm{mL}\right)$ inoculum culture with no media switch. These images are false color overlays of the images collected with the AF488 (green) and AO (red) filter sets.

The amount of biofilm observed after $96 \mathrm{~h}$ on the uncoated and AgNP-coated regions of the half-coated coverslips was greater than was achieved for the silver-free control coverslips at any of the sampled time points up to 96 hours (Supplementary Material, Figure S9). This was the case for triplicate runs of the experiment. This suggests that $P$. fluorescens bacteria respond to the silver stress by forming biofilms, even though in the current situation the source of the stress is the silver ion released from the AgNPs that are adsorbed on the substrate. This supports the recent report that exposure to sublethal concentrations of suspended AgNPs stimulates biofilm development [49]. Since this high biofilm coverage is observed on both the uncoated and coated regions of the same coverslip, it must result from dissolved silver effects. This is consistent with the observations that growth in the bulk in the presence of silver occurred as macroscopic flocs rather than as individually dispersed bacteria. Microbial flocs have many of the same characteristics as biofilms [65] and planktonic growth as flocs was also induced by the silver stress.

Implications of the Inoculum Effect. The primary observation in this work is that an inoculum effect strongly influences how surface-adherent silver nanoparticles affect bacterial surface colonization. The inoculum effect is not considered generally when evaluating antimicrobial surfaces, yet this work shows that it can be a significant factor in the effectiveness of antimicrobial surfaces that are based on release of toxic silver ions. For example, the ASTM standard method E2180 - 07 for "determining the activity of incorporated antimicrobial agents in 
polymeric or hydrophobic materials" recommends testing a single inoculum concentration [66]. The method only considers cell killing at a single time point ( 24 hours is suggested) and does not account for the possibility of long-term recovery of the bacterial population and subsequent surface colonization as occurred in the current surface-adherent AgNP system.

Whereas inhibiting surface colonization is the technological goal of anti-fouling materials, in the context of the environmental implications of silver nanoparticles, the preservation of biofilm formation capability after nanoparticle entry into the environment is the desired situation. This work suggests that silver nanoparticle attachment on natural surfaces after release into the environment may not inhibit biofilm formation over the long term. In addition to the diminished bioavailability of silver bound to planktonic bacteria and/or macromolecular byproducts that was noted here, silver ion complexation to many common environmental ligands, such as humic acid, sulfide, and chloride, has been shown to reduce its toxicity.[15, 37, 44] Therefore, in environmental systems it is possible that unless bacterial populations are very low, the ionic silver released from adherent nanoparticles may not reach levels capable of causing $100 \%$ bacterial viability loss, in which case surface-adhered silver nanoparticles may be unlikely to prevent biofilm formation.

\section{CONCLUSIONS}

Data obtained on the planktonic population response to silver ion and silver nanoparticle exposure and colonization on silver nanoparticle-laden surfaces confirmed the hypothesis that the inhibition of bacterial surface colonization would exhibit an inoculum effect. Evidence was presented that $P$. fluorescens colonization on surfaces decorated with adsorbed silver nanoparticles is a silver ion stress response, and the inoculum effect was evident in the 
observation that prevention of surface colonization occurs only when $100 \%$ of the planktonic bacterial population is killed. This only occurs with a sufficiently low initial inoculum concentration. With higher inoculum concentrations, a small remnant fraction of viable bacteria is sufficient to allow population recovery and surface colonization, proceeding to biofilm formation at long times. The inoculum effect was attributed to silver ion binding to bacteria and/or their macromolecular byproducts and the resulting decrease in free, bioavailable silver ion in solution. Accordingly, the minimal inhibitory concentration and minimal bactericidal concentration, with respect to silver nanoparticles as well as silver ion administered as $\mathrm{AgNO}_{3}$, both increase with increasing concentration of the planktonic bacterial inoculum.

The "anti-fouling" or colonization inhibitory properties of the AgNP-coated glass surfaces used in this work were controlled by the dissolved silver released from the surfaceadhered particles and not by direct bacterial contact with the silver nanoparticles. When colonization occurred, viable bacteria were observed directly on silver nanoparticle-laden surfaces, without the need for any passivating layer of nonviable bacteria that might have shielded newly arriving bacteria from silver.

The current work of course pertains strictly to $P$. fluorescens and immobilized silver nanoparticles. No claim is made about any particular inoculum concentration that should be considered a threshold, above which a sufficient fraction of a bacterial population may survive a silver ion exposure and colonize a silver-laden surface, either for different species or different silver surface presentation formats. It may be anticipated, for example, that the presentation of larger amounts of silver would require higher inoculum concentrations for a population to survive the initial killing and recover. Other species may differ quantitatively, but the possibility of an inoculum effect should be considered when evaluating a toxin-releasing antimicrobial 
surface. Future work should address the prominence of the inoculum effect in the context of surface colonization on silver nanoparticle-laden surfaces or other toxin-releasing surfaces. This should include quantitative comparisons of threshold inoculum concentrations, with a broad variety of bacterial species, including pathogenic ones.

\section{ACKNOWLEDGMENTS}

This material is based upon work supported by the National Science Foundation (NSF) and the Environmental Protection Agency (EPA) under NSF Cooperative Agreements EF0830093 and DBI-1266252, Center for the Environmental Implications of NanoTechnology (CEINT). Any opinions, findings, conclusions or recommendations expressed in this material are those of the author(s) and do not necessarily reflect the views of the NSF or the EPA. This work has not been subjected to EPA review and no official endorsement should be inferred. S.M.W. acknowledges partial support from a National Science Foundation Graduate Research Fellowship. None of the funding sources had input into the design, execution, interpretation or reporting of this research. The authors thank the PPG Industries Colloids, Polymers and Surfaces Laboratory at Carnegie Mellon University and Malvern Instruments for use of light scattering equipment.

\section{REFERENCES}

[1] R.M. Donlan, Emerging Infectious Diseases 7 (2001) 277.

[2] E.M. Hetrick, M.H. Schoenfisch, Chemical Society Reviews 35 (2006) 780.

[3] K. Bazaka, M.V. Jacob, R.J. Crawford, E.P. Ivanova, Applied Microbiology and Biotechnology 95 (2012) 299. 
[4] L.D. Chambers, K.R. Stokes, F.C. Walsh, R.J.K. Wood, Surface \& Coatings Technology 201 (2006) 3642.

[5] C.G. Kumar, S.K. Anand, International Journal of Food Microbiology 42 (1998) 9.

[6] I. Banerjee, R.C. Pangule, R.S. Kane, Advanced Materials 23 (2011) 690.

[7] M. Sharma, S.K. Anand, Journal of Food Science and Technology-Mysore 39 (2002) 573.

[8] M.L.W. Knetsch, L.H. Koole, Polymers 3 (2011) 340.

[9] H.H. Lara, N.V. Ayala-Nunez, L.D.I. Turrent, C.R. Padilla, World Journal of Microbiology \& Biotechnology 26 (2010) 615.

[10] M. Rai, A. Yadav, A. Gade, Biotechnology Advances 27 (2009) 76.

[11] I. Chopra, Journal of Antimicrobial Chemotherapy 59 (2007) 587.

[12] D.R. Monteiro, L.F. Gorup, A.S. Takamiya, A.C. Ruvollo, E.R. Camargo, D.B. Barbosa, International Journal of Antimicrobial Agents 34 (2009) 103.

[13] K. Vasilev, J. Cook, H.J. Griesser, Expert Review of Medical Devices 6 (2009) 553.

[14] C. Damm, H. Munstedt, Appl. Phys. A 91 (2008) 479.

[15] S.M. Wirth, G.V. Lowry, R.D. Tilton, Environmental Science \& Technology 46 (2012) 12687.

[16] O. Choi, C. Yu, G.E. Fernandez, Z.Q. Hu, Water Research 44 (2010) 6095.

[17] D. Roe, B. Karandikar, N. Bonn-Savage, B. Gibbins, J.B. Roullet, Journal of Antimicrobial Chemotherapy 61 (2008) 869.

[18] K. Vasilev, V. Sah, K. Anselme, C. Ndi, M. Mateescu, B. Dollmann, P. Martinek, H. Ys, L. Ploux, H.J. Griesser, Nano Letters 10 (2010) 202.

[19] F. Paladini, M. Pollini, A. Tala, P. Alifano, A. Sannino, Journal of Materials Science-Materials in Medicine 23 (2012) 1983.

[20] C.Y. Flores, C. Diaz, A. Rubert, G.A. Benitez, M.S. Moreno, M. de Mele, R.C. Salvarezza, P.L. Schilardi, C. Vericat, Journal of Colloid and Interface Science 350 (2010) 402.

[21] C.Y. Flores, A.G. Minan, C.A. Grillo, R.C. Salvarezza, C. Vericat, P.L. Schilardi, ACS Appl. Mater. Interfaces 5 (2013) 3149.

[22] F. Furno, K.S. Morley, B. Wong, B.L. Sharp, P.L. Arnold, S.M. Howdle, R. Bayston, P.D. Brown, P.D. Winship, H.J. Reid, Journal of Antimicrobial Chemotherapy 54 (2004) 1019.

[23] D.M. Riley, D.C. Classen, L.E. Stevens, J.P. Burke, American Journal of Medicine 98 (1995) 349.

[24] A. Srinivasan, T. Karchmer, A. Richards, X. Song, T.M. Perl, Infection Control and Hospital Epidemiology 27 (2006) 38. 
[25] J.M. Schierholz, Z. Wachol-Drewek, L.J. Lucas, G. Pulverer, Zentralblatt Fur BakteriologieInternational Journal of Medical Microbiology Virology Parasitology and Infectious Diseases 287 (1998) 411.

[26] M.R. Wiesner, G.V. Lowry, K.L. Jones, M.F. Hochella, R.T. Di Giulio, E. Casman, E.S. Bernhardt, Environmental Science \& Technology 43 (2009) 6458.

[27] C. Marambio-Jones, E.M.V. Hoek, Journal of Nanoparticle Research 12 (2010) 1531.

[28] A.L. Neal, Ecotoxicology 17 (2008) 362.

[29] D.M. Aruguete, M.F. Hochella, Environmental Chemistry 7 (2009) 3.

[30] B.P. Colman, C.L. Arnaout, S. Anciaux, C.K. Gunsch, M.F. Hochella, B. Kim, G.V. Lowry, B.M. McGill, B.C. Reinsch, C.J. Richardson, J.M. Unrine, J.P. Wright, L.Y. Yin, E.S. Bernhardt, PLOS ONE 8 (2013) 1.

[31] K.L. Chen, M. Elimelech, Environmental Science \& Technology 42 (2008) 7607.

[32] E. Navarro, A. Baun, R. Behra, N.B. Hartmann, J. Filser, A.J. Miao, A. Quigg, P.H. Santschi, L. Sigg, Ecotoxicology 17 (2008) 372.

[33] J.W. Costerton, Z. Lewandowski, D.E. Caldwell, D.R. Korber, H.M. Lappinscott, Annual Review of Microbiology 49 (1995) 711.

[34] P. Stoodley, K. Sauer, D.G. Davies, J.W. Costerton, Annual Review of Microbiology 56 (2002) 187.

[35] E. Navarro, F. Piccapietra, B. Wagner, F. Marconi, R. Kaegi, N. Odzak, L. Sigg, R. Behra, Environmental Science \& Technology 42 (2008) 8959.

[36] A.J. Miao, K.A. Schwehr, C. Xu, S.J. Zhang, Z.P. Luo, A. Quigg, P.H. Santschi, Environmental Pollution 157 (2009) 3034.

[37] Z.M. Xiu, J. Ma, P.J.J. Alvarez, Environmental Science \& Technology 45 (2011) 9003.

[38] Z.M. Xiu, Q.B. Zhang, H.L. Puppala, V.L. Colvin, P.J.J. Alvarez, Nano Letters 12 (2012) 4271.

[39] L.Y. Yin, Y.W. Cheng, B. Espinasse, B.P. Colman, M. Auffan, M. Wiesner, J. Rose, J. Liu, E.S. Bernhardt, Environmental Science \& Technology 45 (2011) 2360.

[40] G.A. Sotiriou, S.E. Pratsinis, Environmental Science \& Technology 44 (2010) 5649.

[41] X.Y. Yang, A.P. Gondikas, S.M. Marinakos, M. Auffan, J. Liu, H. Hsu-Kim, J.N. Meyer, Environmental Science \& Technology 46 (2011) 1119.

[42] C.N. Lok, C.M. Ho, R. Chen, Q.Y. He, W.Y. Yu, H.Z. Sun, P.K.H. Tam, J.F. Chiu, C.M. Che, Journal of Proteome Research 5 (2006) 916.

[43] C. Levard, S. Mitra, T. Yang, A.D. Jew, A.R. Badireddy, G.V. Lowry, G.E. Brown, Environmental Science \& Technology 47 (2013) 5738. 
[44] B.C. Reinsch, C. Levard, Z. Li, R. Ma, A. Wise, K.B. Gregory, G.E. Brown, G.V. Lowry, Environmental Science \& Technology

Environ. Sci. Technol. (2012).

[45] V.K.M. Poon, A. Burd, Burns 30 (2004) 140.

[46] I. Sondi, B. Salopek-Sondi, Journal of Colloid and Interface Science 275 (2004) 177.

[47] K. de Prijck, H. Nelis, T. Coenye, Biofouling 23 (2007) 405.

[48] A. Dror-Ehre, H. Mamane, T. Belenkova, G. Markovich, A. Adin, Journal of Colloid and Interface Science 339 (2009) 521.

[49] Y. Yang, P.J.J. Alvarez, Environ. Sci. Technol. Lett. Article ASAP (2015).

[50] A. Taglietti, Y.A.D. Fernandez, E. Amato, L. Cucca, G. Dacarro, P. Grisoli, V. Necchi, P. Pallavicini, L.Pasotti, M. Patrini, Langmuir 28 (2012) 8140.

[51] E. Amato, Y.A. Diaz-Fernandez, A. Taglietti, P. Pallavicini, L. Pasotti, L. Cucca, C. Milanese, P. Grisoli, C. Dacarro, J.M. Fernandez-Hechavarria, V. Necchi, Langmuir 27 (2011) 9165.

[52] Q.L. Feng, J. Wu, G.Q. Chen, F.Z. Cui, T.N. Kim, J.O. Kim, Journal of Biomedical Materials Research 52 (2000) 662.

[53] Z. Guo, J. Xue, T. Liu, X. Song, Y. Shen, H. Wu, Micro \& Nano Letters, IET 9 (2014) 210.

[54] R. Ma, C. Levard, S.M. Marinakos, Y.W. Cheng, J. Liu, F.M. Michel, G.E. Brown, G.V. Lowry, Environmental Science \& Technology 46 (2011) 752.

[55] P.K. Jain, X.H. Huang, I.H. El-Sayed, M.A. El-Sayed, Accounts of Chemical Research 41 (2008) 1578.

[56] S.M. Stocks, Cytometry Part A 61A (2004) 189.

[57] J.M. Meyer, V.A. Geoffroy, N. Baida, L. Gardan, D. Izard, P. Lemanceau, W. Achouak, N.J. Palleroni, Applied and Environmental Microbiology 68 (2002) 2745.

[58] R.J.W. Lambert, M.D. Johnston, Journal of Applied Microbiology 88 (2000) 907.

[59] A.A. Firsov, S.N. Vostrov, O.V. Kononenko, S.H. Zinner, Y.A. Portnoy, Antimicrobial Agents and Chemotherapy 43 (1999) 498.

[60] A.L. Santos, V. Oliveira, I. Baptista, I. Henriques, N.C.M. Gomes, A. Almeida, A. Correia, A. Cunha, Archives of Microbiology 195 (2013) 63.

[61] W. Teughels, N. Van Assche, I. Sliepen, M. Quirynen, Clinical Oral Implants Research 17 (2006) 68.

[62] T.D. Morgan, M. Wilson, Journal of Applied Microbiology 91 (2001) 47. 
[63] N. Mitik-Dineva, J. Wang, V.K. Truong, P. Stoddart, F. Malherbe, R.J. Crawford, E.P. Ivanova, Current Microbiology 58 (2009) 268.

[64] S.P. Valappil, D.M. Pickup, D.L. Carroll, C.K. Hope, J. Pratten, R.J. Newport, M.E. Smith, M. Wilson, J.C. Knowles, Antimicrobial Agents and Chemotherapy 51 (2007) 4453.

[65] I.W. Sutherland, Water Science and Technology 43 (2001) 77.

[66] ASTM Standard E2180-07; ASTM International, West Conshohocken, PA, 2012. 


\section{Figure Captions}

Figure 1. Cell growth indicated by $\mathrm{OD}_{600}(\mathrm{~A})$ and fluorescence emission at $456 \mathrm{~nm}$ with excitation wavelength of $400 \mathrm{~nm}$ (B) measured in the bulk liquid bathing coverslips. Except for a slight lag, growth in the $\mathrm{OD}_{600}=0.01$ cultures exposed to the AgNP coated coverslips (open black squares) was similar to growth in the silver-free control cultures (closed black squares). When an initial $\mathrm{OD}_{600}=0.001$ culture was used, growth was significantly delayed in the culture that was incubated with AgNP half-coated coverslips (open grey circles) compared to the case with silver-free coverslips (closed grey circles). Fluorescence (B) produced by the bacteria in AgNP exposed cultures eventually recovered to values similar to the silver-free control. Error bars represent standard deviations based on measurements from three separate experiments.

Figure 2. Dissolved silver concentration in the bulk liquid bathing AgNP half-coated coverslips showed an increase in dissolved silver with time in the cell-free controls (black bars). When these samples were filtered on $3 \mathrm{kDa}$ ultrafiltration devices, silver concentration was not significantly affected $(\mathrm{P}=0.3)$ (open bars). Large decreases in dissolved silver concentrations were observed when the bulk liquid from tubes containing cells from initial inocula corresponding to $\mathrm{OD}_{600}=0.001$ (grey bars) or $\mathrm{OD}_{600}=0.01$ (not detected) were filtered. No silver was detected in any of the $\mathrm{OD}_{600}=0.01$ filtrates. The black line $(\times)$ shows the $\mathrm{OD}_{600}$ of the $\mathrm{OD}_{600}$ $=0.001$ starting culture at the various time points.

Figure 3. Free silver concentrations for $\mathrm{AgNO}_{3}$ added to planktonic $P$. fluorescens cultures in MDM, as measured by ICP-MS after filtration with a $3 \mathrm{kDa}$ cutoff. Cell-free controls (open diamonds) showed minimal decreases in free silver after filtration while $\mathrm{OD}_{600}=0.001$ (open circles), $\mathrm{OD}_{600}=0.01$ (open squares) and $\mathrm{OD}_{600}=0.045$ (open triangles) bacterial cultures decreased the free silver concentration to different degrees. The inset highlights low concentration data.

Figure 4. Representative images of BacLight stained bacteria adhered to a silver-free control coverslip (A), the uncoated region of a coverslip half-coated with AgNPs (B), and the AgNP coated region of the half-coated coverslip (C) after $20 \mathrm{~h}$ incubation with the $\mathrm{OD}_{600}=0.01\left(\sim 1 \times 10^{7}\right.$ $\mathrm{CFU} / \mathrm{mL}$ ) inoculum $P$. fluorescens culture. These are false color overlays of images collected with the AF488 (green) and AO (red) filter sets. The average viability (black bars) and cell count per image (frame size is $37300 \mu \mathrm{m}^{2}$ ) (grey bars) are plotted in (D). Error bars represent one standard deviation based on 4, 3, and 6 replicates for the silver-free, uncoated, and AgNP coated conditions, respectively. For each replicate experiment, at least five different, randomly selected images from each of the surface regions were analyzed.

Figure 5. BacLight stained bacterial biofilms adhered to a silver-free control coverslip (A) and an AgNP-coated coverslip (B) after a total of $68 \mathrm{~h}$ growth (from $\mathrm{OD}_{600}=0.01$ starting culture, transferred to new MDM after $20 \mathrm{~h}$, second transfer after an additional $24 \mathrm{~h}$ ). Large clusters indicate significant biofilm formation, even on the AgNP-coated surface. 
Figure 6. Representative images of BacLight stained bacteria adhered to a silver-free control coverslip (A), the uncoated region of a coverslip half-coated with AgNPs (B), and the AgNPcoated region of the half-coated coverslip (C) after $20 \mathrm{~h}$ incubation with the $\mathrm{OD}_{600}=0.001$ $\left(\sim 1 \times 10^{6} \mathrm{CFU} / \mathrm{mL}\right)$ inoculum $P$. fluorescens culture. These are false color overlays of images collected with the AF488 (green) and AO (red) filter sets. "Viable" cells in these images appear as bright green, while "non-viable" cells appear as very faint red (marked with arrows). The same field of view from (C) was also imaged in darkfield (D) to show that AgNPs remain adhered to the coverslip. Large bright objects in (D) are cells, both viable and non-viable, while small dots show light scattered from adherent AgNPs. Every cell observed in (C) appears in (D).

Figure 7. Average viability (black) and number of adherent cells per image (frame size is 37300 $\mu \mathrm{m}^{2}$ ) (grey) on silver-free control coverslips and the uncoated and AgNP-coated regions of halfcoated coverslips after $20 \mathrm{~h}$ incubation with the $\mathrm{OD}_{600}=0.001\left(\sim 1 \times 10^{6} \mathrm{CFU} / \mathrm{mL}\right)$ inoculum $P$. fluorescens culture. Error bars for the viability results represent standard deviations based on 5, 3 , and 5 replicates in the silver-free, uncoated, and AgNP-coated cases, respectively. For the cell counts, there were 7, 9, and 11 replicates. For each replicate experiment, at least five different images from each of the different surface regions were analyzed.

Figure 8. Representative images of BacLight stained bacteria adhered to the uncoated (A,B,C) and AgNP-coated (D,E,F) regions of half-coated coverslips after $48 \mathrm{~h}$ (A,D), $72 \mathrm{~h}(\mathrm{~B}, \mathrm{E})$ and $96 \mathrm{~h}$ $(\mathrm{C}, \mathrm{F})$ of growth from $\mathrm{OD}_{600}=0.001\left(\sim 1 \times 10^{6} \mathrm{CFU} / \mathrm{mL}\right)$ inoculum culture with no media switch. These images are false color overlays of the images collected with the AF488 (green) and AO (red) filter sets. 


\section{Graphical Abstract}

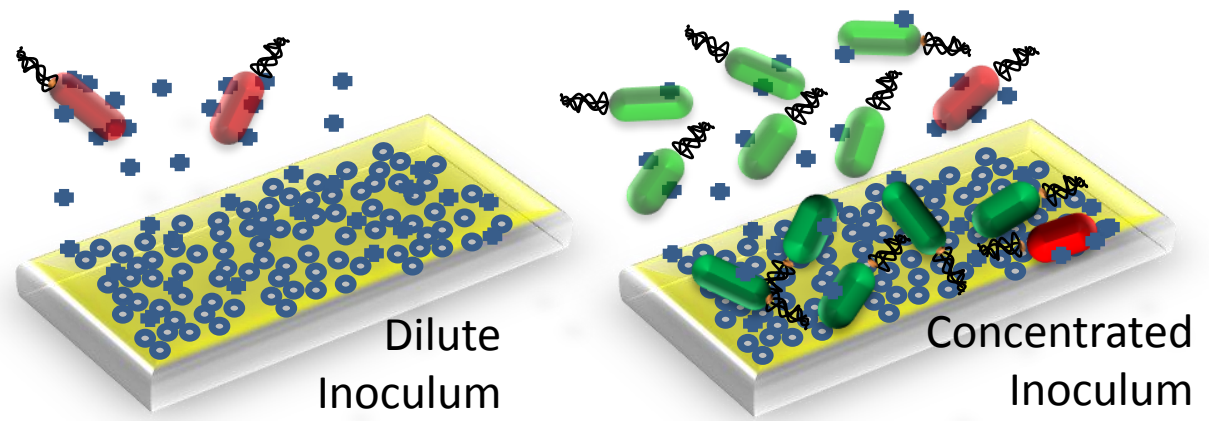

